Original Article

\title{
Comparisons of knee and ankle joint angles and ground reaction force according to functional differences during single-leg drop landing
}

\author{
Kewwan Kim, PhD ${ }^{1)}$, Kyoungkyu JeOn, $\mathrm{PhD}^{2)^{*}}$ \\ 1) Division of Sport Science, Incheon National University, Republic of Korea \\ 2) Sport Science Institute, Incheon National University: 119 Academy-ro, Yeonsu-gu, Incheon 22012, \\ Republic of Korea
}

\begin{abstract}
Purpose] The purpose of this study was to determine potential predictors of functional instability of the knee and ankle joints during single-leg drop landing based on the prior history of injury. [Subjects and Methods] The subjects were 24 collegiate soccer players without pain or dysfunction. To compare the differences between the stable and unstable sides during single-leg drop landing, 8 motion analysis cameras and a force plate were used. The Cortex 4 software was used for a biomechanical analysis of 3 events. An independent t-test was used for statistical comparison between both sides; $\mathrm{p}<0.05$ indicated significance. [Results] The knee joint movements showed gradual flexion in the sagittal plane. The unstable-side ankle joint showed plantar flexion of approximately $2^{\circ}$ relative to the stable side. In the coronal plane, the unstable-side knee joint differed from the stable side in its tendency for valgus movement. The unstable-side ankle joint showed contrasting movement compared with the stable side, and the difference was significant. Regarding the vertical ground reaction force, the stable side showed maximum knee flexion that was approximately 0.1 BW lower than that of the unstable side. [Conclusion] Increasing the flexion angle of the knee joint can help prevent injury during landing.

Key words: Drop landing, Knee and ankle joint, Ground reaction force
\end{abstract}

(This article was submitted Nov. 18, 2015, and was accepted Dec. 23, 2015)

\section{INTRODUCTION}

Chronic instability of the major leg joints occurs frequently in athletes who play soccer, basketball, rugby, and other sports that involve repetitive joint movements ${ }^{1,2}$. The risk of injury appears to depend on the functional differences between the stable and unstable sides in almost all movement patterns, including sudden stops or direction changes. The knee and ankle joints are the major areas susceptible to injury in such conditions, and functional damage to the leg is a frequent cause of pain.

Instability of the knee joints leads to restricted movement within the range of motion (ROM), which then results in a cycle of repeated instability in the joints ${ }^{3,4)}$. Consequently, improper functional movements change the load applied to the legs ${ }^{5)}$ and can lead to injury to the musculoskeletal system of the legs. Ankle joint sprains are common among active people, and acute sprains tend to repeatedly recur ${ }^{6-8)}$. Moreover, $>70 \%$ of individuals who experienced an ankle sprain also experience similar symptoms such as additional and repeated instability from re-injury and functional abnormalities ${ }^{9)}$. Even when not considering structural instability, the development of functional instability indicates the vulnerability of knee and ankle joints to injury during repetitive activity patterns ${ }^{10)}$ and during active movements involving sudden participation in exercise and high intensity exercise ${ }^{11)}$, which may present as chronic problems in elite athletes ${ }^{12-14)}$.

Successful drop landing requires muscle strength, stability, and additional capabilities of the major joints, which are important factors influencing protection against injury to the joint facets ${ }^{15,16)}$. Moreover, jumping and landing, which occur

*Corresponding author. Kyoungkyu Jeon (E-mail: jeonkay@gmail.com)

(C2016 The Society of Physical Therapy Science. Published by IPEC Inc.

This is an open-access article distributed under the terms of the Creative Commons Attribution Non-Commercial No Derivatives (by-nc-nd) License $<$ http://creativecommons.org/licenses/by-nc-nd/4.0/>. 
frequently during sporting events, can be soft or rigid, depending on the biomechanical energy loss ${ }^{17}$, 18), and can be a cause of injury along with instability ${ }^{19,20}$. As the force of impact of ground reaction force (GRF) is greater during rigid landing than during soft landing, the presence of any abnormality during single-leg landing can be easily identified; moreover, based on these findings, the causes of such a decrease in major joints and muscles of the lower extremity can also be determined ${ }^{21)}$.

Accordingly, the instability of the major leg joints may manifest in various forms during daily activities or participation in exercise $^{12,14,18)}$. If individuals continue to participate in complex functional activities without improving the instability, the instability can subsequently progress to an abnormality and can consequently result in complex injuries. The purpose of this study was to assess the stability of functional movements in the major leg joints in order to elucidate basic biomechanical data of the potential predictors of functional instability in the knee and ankle joints of soccer players based on the results of single-leg drop landing.

\section{SUBJECTS AND METHODS}

In this study, the subjects were 24 collegiate soccer players who had experienced injuries related to knee and ankle joint instability but were currently able to participate in matches without pain or dysfunction. The mean age, height, and weight of the participants were $21.3 \pm 1.4$ years, $179.3 \pm 5.3 \mathrm{~cm}$, and $75.0 \pm 6.3 \mathrm{~kg}$, respectively. All the subjects understood the purpose of this study and provided written informed consent prior to participants in the study in accordance with the ethical standards of the Declaration of Helsinki.

Eight-motion analysis cameras (2 Raptor and 6 Eagle cameras, Motion Analysis Corp., Snata Rosa, CA, USA) were employed for recording biomechanical measurements of the knee and ankle joints during single-leg drop landing. To ensure accurate testing, the participant was positioned at the center of the location where the motion would be performed prior to measurement, and the cameras were set up as follows; 3 cameras each on the left and right sides and 1 camera each on the front and back sides within $5 \mathrm{~m}$ of the participant; the reference coordinate points were adjusted with the height of the lens in order to completely cover the entire ROM. In addition, calibration was also performed establish spatial coordinates. The sampling rate of the shooting speed of the motion analysis cameras was set at $120 \mathrm{frames} / \mathrm{s}$, and the accuracy was set at within $0.3 \mathrm{~mm}$. Moreover, for biomechanical measurements, a force plate (OR-5-2000, AMTI Inc., Watertown, MA, USA) was used, with a sampling rate of $1,200 \mathrm{~Hz} / \mathrm{s}$. The motion analysis and GRF data were synchronized via an analog-digital converter (NI USB-6218, Instruments Hungray, Debrecen, Hungary).

To calculate the variables of the human body, 19 reflective markers were attached to the legs (mid sacral, right and left ASIS (anterior superior iliac spine), right and left thigh and shank, right and left lateral epicondyle of the knee, right and left lateral malleolus ankle joint, right and left toe and heel, right and left medial epicondyle of the knee, and right and left medial malleolus ankle joint), and an anatomically static posture was measured for approximately $3 \mathrm{~s}$. Thereafter, 4 markers attached to the inner sides of the left and right knee and ankle joints were removed, and measurements were taken using a total of 15 markers. For the measurements, a drop-landing movement was performed individually from above a vertical plane that was approximately $30 \mathrm{~cm}$ based on previous studies ${ }^{2,22-24)}$ the stable side was measured first, followed by the unstable side. To assess stability, a motion involving the maintenance of balance for over $3 \mathrm{~s}$ after landing was used for the analysis.

Cortex 4 was used for data processing, whereas a linked rigid body system was used to convert the center point of the body segments into coordinates. The center of gravity and center position of the body were calculated using body segment index parameter data. Planar (two-dimensional) data obtained from the 8 motion analysis cameras were converted to threedimensional data via the nonlinear transformation (NLT) method. To eliminate noise errors during data processing, a cutoff frequency of $8 \mathrm{~Hz}$ was used for Butterworth low-pass digital filtering by Cortex 4. Moreover, smoothing was performed on the GRF data with a cut-off frequency of $50 \mathrm{~Hz}$.

In the present study, the global coordinates for the major joints in the leg were defined as the $\mathrm{X}$ (anteroposterior), $\mathrm{Y}$ (mediolateral), and Z (vertical) axes. For biomechanical analysis, 3 events were used: the point of generating GRF or initial foot contact on the plate (IC), the point of achieving maximum vertical value of the GRF or maximum ground reaction force (MGRF), and the point of achieving maximum knee joint flexion or maximum knee flexion (MKF). The knee and ankle joint movements during single-leg drop landing were analyzed in the sagittal and coronal planes. Accordingly, the movements considered included flexion $(+)$ and extension $(-)$ of the knee joints and dorsiflexion $(+)$ and plantar flexion $(-)$ of the ankle joints in the sagittal plane, as well as valgus $(+)$ and varus $(-)$ movements of the knee joints and inversion $(+)$ and extraversion (-) of the ankle joints in the coronal plane.

All the measured data were calculated as means and standard deviations using IBM SPSS Statistics 20.0 (IBM Corp., Armonk, NY, USA). To compare the differences in the basic biomechanical levels between the stable and unstable sides for single-leg drop-landing based on the prior history of injury, the independent sample t-test was used, with $\mathrm{p}<0.05$ indicating statistical significance.

\section{RESULTS}

The results of the comparison of angles of the knee and ankle joints in the sagittal and coronal planes at the 3 events during single-leg drop landing, which could help predict leg injuries, are as shown in Table 1. The knee and ankle joint angles in the 
Table 1. Comparisons of the angles of the knee and ankle joint (unit: deg)

\begin{tabular}{llrrrr}
\hline \multirow{2}{*}{ Event } & \multirow{2}{*}{ Joint } & \multicolumn{2}{c}{ Sagittal Plane } & \multicolumn{2}{c}{ Frontal Plane } \\
\cline { 3 - 6 } & Knee & Stable & Unstable & Stable & Unstable \\
\hline \multirow{2}{*}{ IC } & $13.6 \pm 5.0$ & $13.4 \pm 5.5$ & $-5.8 \pm 3.1$ & $2.3 \pm 3.5^{* * *}$ \\
& Ankle & $-31.7 \pm 6.3$ & $-34.6 \pm 7.2$ & $-10.8 \pm 6.3$ & $16.9 \pm 7.7^{* * *}$ \\
\multirow{2}{*}{ MGRF } & Knee & $31.0 \pm 6.5$ & $32.3 \pm 6.5$ & $-9.0 \pm 4.0$ & $3.5 \pm 4.1^{* * *}$ \\
& Ankle & $-8.2 \pm 6.0$ & $-8.3 \pm 6.2$ & $-3.6 \pm 7.9$ & $5.3 \pm 7.8^{* * *}$ \\
\multirow{2}{*}{ MKF } & Knee & $53.3 \pm 8.9$ & $48.5 \pm 9.6$ & $-10.4 \pm 5.1$ & $3.5 \pm 5.3^{* * *}$ \\
& Ankle & $4.4 \pm 5.1$ & $2.4 \pm 4.9$ & $1.7 \pm 7.9$ & $-4.3 \pm 7.1^{* * *}$ \\
\hline
\end{tabular}

Values are shown as the mean $\pm \mathrm{SD}, * * * \mathrm{p}<0.0001$. IC: initial foot contact on plate; MGRF: maximum vertical ground reaction force (GRF); MKF: Maximum knee flexion

Table 2. Comparisons of vertical GRFs (unit: BW)

\begin{tabular}{lcc}
\hline \multirow{2}{*}{ Event } & \multicolumn{2}{c}{ Vertical GRF (BW) } \\
\cline { 2 - 3 } & Stable & Unstable \\
\hline IC & $0.2 \pm 0.2$ & $0.2 \pm 0.2$ \\
MGRF & $3.1 \pm 0.7$ & $3.1 \pm 0.4$ \\
MKF & $1.7 \pm 0.5$ & $1.6 \pm 0.4$ \\
\hline
\end{tabular}

Values are shown as the mean \pm SD. GRF: grounf reaction force; IC: initial foot contact on plate; MGRF: maximum vertical GRF; MKF: Maximum knee flexion

sagittal plane did not significantly differ between the stable and unstable sides, whereas those in the coronal plane showed significant differences at all 3 events. After dividing the GRF during the vertical movement at the 3 events by the body weight of the participant for standardization and comparison, there was no significant difference between the bilateral sides at any of the three events (Table 2).

\section{DISCUSSION}

The purpose of this study was to elucidate basic biomechanical data of the potential predictors of instability causing leg injury based on the results of single-leg drop landing. By comparing the knee and ankle joint angles at 3 events (IC, MGRF, and MKF), the knee joint movement on the stable and unstable sides in the sagittal plane showed gradual flexion. In particular, at the MKF, the mean angle of knee flexion on the stable side was $53.3^{\circ}$, which represented a difference of $4.8^{\circ}$ from the value $\left(48.5^{\circ}\right)$ on the unstable side. Such an increase in the knee flexion angle was consistent with the results from previous studies, which indicated that such increases can reduce damage to the anterior cruciate ligament (ACL) by promoting a more stable landing motion and can have a positive influence on ankle joint support ${ }^{25}$,26). In contrast, the ankle joints on the stable side showed plantar flexion from IC to the MGRF, followed by dorsiflexion at MKF. Moreover, the ankle joints on the unstable side showed a similar angle and movement as the stable side at all 3 events, although the ankle joint on the unstable side showed approximately $2^{\circ}$ of plantar flexion at MKF relative to the stable side. The increased ROM during dorsiflexion of the ankle joints holds the tibia at the front, when load is applied, to increase the stability of the ankles, which is consistent with the findings in previous studies ${ }^{10,12)}$. These findings support the observation of greater stability on the stable side than on the unstable side.

In the coronal plane, the stable side of the knee joint showed gradual varus movement from IC to MKF, whereas the unstable side of the knee joint indicated a difference from the stable side in terms of a tendency for valgus movement from IC to MKF. During landing, the presence of a large valgus angle can induce damage to the ACL and medial ligament. Hence, the tendency for valgus movement in the present study may be attributed to the restriction of stable support. The ankle joints on the stable side showed inversion from IC to the MGRF, followed by extraversion at MFK, whereas those on the unstable side showed extraversion to inversion. Moreover, comparisons of the data between the unstable and stable sides indicated significant differences. It is speculated that such different between both sides may be due to the restriction of the ROM of inversion and the improved stability of the ankle joints ${ }^{27}$.

Accordingly, the changes in the movements of the knee and ankle joints during drop landing in the present study support the results of previous studies, wherein multiple lesions in the longitudinal and lateral directions, along with pain, were reported to occur following repeated motion that requires weight bearing in athletes and in active youths ${ }^{2,11,28)}$. Thus, a representative injury mechanism of the knee joint reportedly occurs, primarily when the knee is flexed and in the valgus 
state $^{29}$. Moreover, in order to absorb the GRF that is generated during landing, the ankle joint undergoes movement from plantar flexion to dorsiflexion ${ }^{30}$. The knee is an important joint for absorbing shock during drop landing, and is closely associated with the $\mathrm{GRF}^{31)}$. As represented by the change in angles in the present study, an increase in the flexion and internal rotation of the knees and ankles during drop landing would absorb the impact delivered to the body, thus facilitating stable landing. Based on the findings from previous studies and the current analyses, no significant differences were observed in the 3 events, and the MKF on the stable side appeared to be $0.1 \mathrm{BW}$ lower than that on the unstable side. These results are consistent with those of a previous study ${ }^{32}$, which reported that an increase in the size of the maximum vertical GRF increases the force delivered to each joint at contact with the ground and hence easily exposes them to injury. Therefore, as suggested in the report by Kernozek et al. ${ }^{33)}$, increasing the flexion angle of the knee joints can be viewed as a strategy for preventing injury during landing.

In studies on unstable knee and ankle joints involving landing after jumping, it has been observed that some athletes frequently engage in jumping and landing movements in competitive practices and competition ${ }^{10,15)}$. To achieve a more stable landing, an unnecessary expression of muscle strength occurs, which may also serve as another factor of instability ${ }^{6,14)}$. In fact, chronic instability can be caused by various factors and can progress to abnormalities when other functional activities are performed ${ }^{12,14)}$. Moreover, the entire body, not just the joints, is involved in absorbing the impact during landing; hence, future studies that explain the correlations with even more joint functions are needed. Strategic rehabilitation programs based on information obtained through such fundamental studies are needed to improve instability.

\section{ACKNOWLEDGEMENT}

This work was supported by the National Research Foundation of Korea Grant funded by the Korean Government (NRF2012S1A5A2A01019565).

\section{REFERENCES}

1) Peters JW, Trevino SG, Renstrom PA: Chronic lateral ankle instability. Foot Ankle, 1991, 12: 182-191. [Medline] [CrossRef]

2) Sinsurin K, Vachalathiti R, Jalayondeja W, et al.: Different sagittal angles and moments of lower extremity joints during single-leg jump landing among various directions in basketball and volleyball athletes. J Phys Ther Sci, 2013, 25 : 1109-1113. [Medline] [CrossRef]

3) Ferber R, Kendall KD, Farr L: Changes in knee biomechanics after a hip-abductor strengthening protocol for runners with patellofemoral pain syndrome. J Athl Train, 2011, 46: 142-149. [Medline] [CrossRef]

4) Witvrouw E, Lysens R, Bellemans J, et al.: Intrinsic risk factors for the development of anterior knee pain in an athletic population. A two-year prospective study. Am J Sports Med, 2000, 28: 480-489. [Medline]

5) Munkh-Erdene B, Sakamoto M, Nakazawa R, et al.: Relationship between hip muscle strength and kinematics of the knee joint during single Leg squatting and dropping. J Phys Ther Sci, 2011, 23: 205-207. [CrossRef]

6) Beynnon BD, Renström PA, Alosa DM, et al.: Ankle ligament injury risk factors: a prospective study of college athletes. J Orthop Res, 2001, 19: 213-220. [Medline] [CrossRef]

7) Fernandez WG, Yard EE, Comstock RD: Epidemiology of lower extremity injuries among U.S. high school athletes. Acad Emerg Med, 2007, 14: 641-645. [Medline] [CrossRef]

8) Hootman JM, Dick R, Agel J: Epidemiology of collegiate injuries for 15 sports: summary and recommendations for injury prevention initiatives. J Athl Train, 2007, 42: 311-319. [Medline]

9) Anandacoomarasamy A, Barnsley L: Long term outcomes of inversion ankle injuries. Br J Sports Med, 2005, 39: e14, discussion e14. [Medline] [CrossRef]

10) Hertel J, Olmsted-Kramer LC: Deficits in time-to-boundary measures of postural control with chronic ankle instability. Gait Posture, 2007, 25: 33-39. [Medline] [CrossRef]

11) Yi CH, Park SY, Lee SH: Gender differences in knee angle on landing from a drop-jump: kinematic data in young adults. J Phys Ther Sci, 2004, 16: 1-5. [CrossRef]

12) Hertel J: Functional anatomy, pathomechanics, and pathophysiology of lateral ankle instability. J Athl Train, 2002, 37: 364-375. [Medline]

13) Kim H, Chung E, Lee BH: A comparison of the foot and ankle condition between elite athletes and non-athletes. J Phys Ther Sci, 2013, 25: 1269-1272. [Medline] [CrossRef] 
14) McKeon PO, Hertel J: Systematic review of postural control and lateral ankle instability, part I: can deficits be detected with instrumented testing. J Athl Train, 2008, 43: 293-304. [Medline] [CrossRef]

15) Ross SE, Guskiewicz KM, Yu B: Single-leg jump-landing stabilization times in subjects with functionally unstable ankles. J Athl Train, 2005, 40: 298-304. [Medline]

16) Wikstrom EA, Naik S, Lodha N, et al.: Balance capabilities after lateral ankle trauma and intervention: a meta-analysis. Med Sci Sports Exerc, 2009, 41: 1287-1295. [Medline] [CrossRef]

17) McKeon PO, Ingersoll CD, Kerrigan DC, et al.: Balance training improves function and postural control in those with chronic ankle instability. Med Sci Sports Exerc, 2008, 40: 1810-1819. [Medline] [CrossRef]

18) Hoch MC, McKeon PO: Joint mobilization improves spatiotemporal postural control and range of motion in those with chronic ankle instability. J Orthop Res, 2011, 29: 326-332. [Medline] [CrossRef]

19) Kaneko M, Sakuraba K: Association between femoral anteversion and lower extremity posture upon single-leg landing: implications for anterior cruciate ligament injury. J Phys Ther Sci, 2013, 25: 1213-1217. [Medline] [CrossRef]

20) Chang JS, Kwon YH, Choi JH, et al.: Gender differences in lower extremity kinematics and kinetics of the vertical ground reaction force peak in drop-landing by flatfooted subjects. J Phys Ther Sci, 2012, 24: 267-270. [CrossRef]

21) Brown CN, Mynark R: Balance deficits in recreational athletes with chronic ankle instability. J Athl Train, 2007, 42: 367-373. [Medline]

22) Teoh JC, Low JH, Lim YB, et al.: Investigation of the biomechanical effect of variable stiffness shoe on external knee adduction moment in various dynamic exercises. J Foot Ankle Res, 2013, 6: 39-47. [Medline] [CrossRef]

23) Fong CM, Blackburn JT, Norcross MF, et al.: Ankle-dorsiflexion range of motion and landing biomechanics. J Athl Train, 2011, 46: 5-10. [Medline] [CrossRef]

24) Orishimo KF, Kremenic IJ, Pappas E, et al.: Comparison of landing biomechanics between male and female professional dancers. Am J Sports Med, 2009, 37: 2187-2193. [Medline] [CrossRef]

25) Delahunt E, Monaghan K, Caulfield B: Changes in lower limb kinematics, kinetics, and muscle activity in subjects with functional instability of the ankle joint during a single leg drop jump. J Orthop Res, 2006, 24: 1991-2000. [Medline] [CrossRef]

26) Mandelbaum BR, Silvers HJ, Watanabe DS, et al.: Effectiveness of a neuromuscular and proprioceptive training program in preventing anterior cruciate ligament injuries in female athletes: 2-year follow-up. Am J Sports Med, 2005, 33: 1003-1010. [Medline] [CrossRef]

27) Lepers R, Hausswirth C, Maffiuletti N, et al.: Evidence of neuromuscular fatigue after prolonged cycling exercise. Med Sci Sports Exerc, 2000, 32: 1880-1886. [Medline] [CrossRef]

28) Nijs J, Van Geel C, Van der auwera C, et al.: Diagnostic value of five clinical tests in patellofemoral pain syndrome. Man Ther, 2006, 11: 69-77. [Medline] [CrossRef]

29) Agel J, Evans TA, Dick R, et al.: Descriptive epidemiology of collegiate men's soccer injuries: National Collegiate Athletic Association Injury Surveillance System, 1988-1989 through 2002-2003. J Athl Train, 2007, 42: $270-277$. [Medline]

30) Brazen DM, Todd MK, Ambegaonkar JP, et al.: The effect of fatigue on landing biomechanics in single-leg drop landings. Clin J Sport Med, 2010, 20: 286-292. [Medline] [CrossRef]

31) Chappell JD, Creighton RA, Giuliani C, et al.: Kinematics and electromyography of landing preparation in vertical stop-jump: risks for noncontact anterior cruciate ligament injury. Am J Sports Med, 2007, 35: 235-241. [Medline] [CrossRef]

32) Kim CJ, Lee KI, Hong WK: The effect of asymmetric muscle force in the lower extremity on dynamic balance on during drop landing. Korean J Sport Biomech, 2011, 21: 173-179. [CrossRef]

33) Kernozek TW, Torry MR, Iwasaki M: Gender differences in lower extremity landing mechanics caused by neuromuscular fatigue. Am J Sports Med, 2008, 36: 554-565. [Medline] [CrossRef] 